\title{
Financiamento da educação básica: e a escola como agência multifuncional na sociedade neoliberal. São Paulo: BT - Acadêmica, 2020. v. 1.
}

\author{
Viviane Freitas \\ Mestra em Educação \\ Universidade Nove de Julho - UNINOVE \\ São Paulo, SP - Brasil \\ vivi_freitas13@yahoo.com.br
}

\section{Para citar- (ABNT NBR 6023:2018)}

FREITAS, Viviane. Resenha. Eccos - Revista Cientifica, São Paulo, n. 57, p. 1-3, e18635, abr./jun., 2021. Financiamento da Educação Básica: e a escola como agência multifuncional na sociedade neoliberal. São Paulo: BT - Acadêmica, 2020. v. 1. Disponível em:

https://doi.org/10.5585/eccos.n57.18635.

A obra Financiamento da Educação Básica: e a escola como agência multifuncional na

sociedade neoliberal é resultado da coletânea dos estudos realizados por pesquisadores e pesquisadoras do "Programa de Mestrado Profissional em Gestão e Práticas Educacionais" da Universidade Nove de Julho, que tem fomentado discussões e reflexões que resultaram na referida produção acadêmica.

Também incentivou a levar a campo as inquietações e a realizar investigações por meio de estudos de caso em diversas escolas com características diferentes (mesmo que, por vezes, pertencentes à mesma rede de ensino). São pesquisas que adentram as escolas com o intuito de investigar as mais diversas faces do processo de financiamento da Educação Básica.

Ao "seguir o dinheiro" (acompanhar o processo de financiamento) é possível colocar o "dedo na ferida" e refletir sobre a Educação Básica e suas necessidades mais elementares. Dessa forma é possível constatar que essas demandas são negligenciadas por políticas públicas, que precarizam e dificultam que esse financiamento seja usado de forma eficaz para as necessidades reais.

O livro tem como objetivo entender esse financiamento em uma sociedade que passa por mais uma crise neoliberal, que faz parte dos ciclos da sociedade capitalista. Como base metodológica para os estudos realizados nos escritos é apresentado o roteiro de observação de Libâneo (2013). As organizadoras também chamam a atenção para a diversificação teórica utilizada em cada capítulo, já que foi respeitada a pluralidade de correntes teóricas às quais os pesquisadores se filiam. 
Diante dessa coletânea de pesquisas temos a possibilidade de compreender um pouco mais sobre a Educação Básica, a partir das experiências, pesquisas e dos artigos resultantes do processo de formação desses pesquisadores que procuram colocar luz em um tema que é elementar para a compreensão dos processos educacionais.

Dito isso, vamos explicitar mais detalhadamente as temáticas abordadas: terceirização dos serviços escolares (limpeza, segurança e cozinha), redes conveniadas, formação de professores, gestão democrática, nova gestão pública, avaliações externas, autonomia ou a falta de autonomia dos profissionais da educação e, trazendo como consequência, o adoecimento. Todas essas temáticas são influenciadas diretamente pelo financiamento público: como ele é feito (ou não) e quais as consequências para a educação pública.

Compreender o financiamento da Educação Básica não é um processo simples. Apesar da Lei da Transparência, Lei do Acesso à Informação e dos recursos instituídos em normas, leis e programas, digamos que ainda há um véu sobre essa temática. Muitos educadores não compreendem o processo de financiamento e de que que forma esse dinheiro é gasto. Para a sociedade então, isso é ainda mais complexo. Portanto, vale ressaltar que a leitura do referido livro não sanará todas as dúvidas, mas contribuirá com o processo de compreensão desse cenário.

A autonomia da gestão escolar em relação aos gastos com a educação é relativa. Apresenta algumas "brechas" que permitem certa autonomia. Entretanto, o processo de financiamento é permeado por burocracias que desestimulam a gestão no que se refere a incentivar a participação da comunidade escolar nos processos. É por isso, que esses espaços muitas vezes são desconhecidos por pais, funcionários e pela comunidade de forma geral. Nesse cenário, perde-se a gestão democrática, muito mais por uma questão de dificultadores burocráticos do que pela real falta de interesse no assunto, tanto por parte da gestão, quanto por parte da comunidade.

Essas são algumas das questões abordadas nesses estudos. Trata-se de um livro instigador, sobretudo no que diz respeito à proposição de sérias reflexões sobre a aplicação do dinheiro público na educação: sua utilização, entraves e dificultadores para fazê-la e desdobramentos para a qualidade da educação e para a saúde dos trabalhadores da educação. Quando essas questões administrativas são abordadas, o gerencialismo - que adentrou o universo educacional trazendo os preceitos do mundo empresarial - instaura um cenário composto por cobranças e preocupações centradas na "qualidade" empresarial em detrimento de uma educação que seja emancipatória para os alunos e trabalhadores. 
Alguns caminhos são apontados pelas pesquisas no escopo desses escritos: um deles seria integrar as programações nos entes federativos, nas secretarias e órgãos. Assim, o que pensam, planejam e projetam estaria em maior consonância com o "chão da escola". Isso justamente porque os projetos e a realidade precisam encontrar-se em políticas públicas que visem a diminuição desse abismo constatado pelas pesquisas que compõem esse livro. A participação nos processos é uma outra possibilidade identificada pela obra. O ideal é construir uma gestão que seja eficaz nos processos de inclusão da comunidade nas tomadas de decisões que afetam o escopo da escola e consequentemente, todo o processo educacional.

Para Rosemary Roggero, a partir de então seria possível inverter a lógica vigente, alterar a dinâmica dos processos e abrir uma possibilidade de autonomia, com processos mais participativos e transparentes. Consequentemente, os recursos destinados à educação deixarão de ser indecifrável.

Os autores do livro fazem reflexões a partir das pesquisas apresentadas, que possibilitam aos leitores a compreensão da importância do financiamento no processo de democratização da educação pública. Essas reflexões mostram que esse caminho ainda é árduo, apesar de alguns dispositivos legais favorecerem esse processo. Ainda é necessário criar uma cultura de participação de todos os entes envolvidos na dinâmica escolar, num processo que privilegie a transparência em relação ao uso dos recursos disponíveis.

\section{Referências}

ROGGERO, R. (Org.); PISANESCHI, Lucilene Schunck C (Org.); COSTA, Ana A. (Org.) . Financiamento da Educação Básica: e a escola como agência multifuncional na sociedade neoliberal. São Paulo: BT - Acadêmica, 2020. v. 1. 